\title{
Obstructive Sleep Apnea, Excessive Daytime Sleepiness, and Road Traffic Accidents among Interstate Commercial Vehicle Drivers in Nigeria
}

\author{
Daniel O. Obaseki, ${ }^{1}$ Gregory E. Erhabor, ${ }^{1}$ Josephine E. Obaseki, ${ }^{2}$ \\ Ibukun Abidoye, ${ }^{3}$ Akinjide Adebisi, ${ }^{4}$ and Babatunde Olaiya ${ }^{4}$ \\ ${ }^{1}$ Department of Medicine, Obafemi Awolowo University, Ile-Ife 220282, Nigeria \\ ${ }^{2}$ Department of Preventive and Community Dentistry, Obafemi Awolowo University Teaching Hospital, Ile-Ife 220282, Nigeria \\ ${ }^{3}$ Department of Radiology, Obafemi Awolowo University Teaching Hospital, Ile-Ife 220282, Nigeria \\ ${ }^{4}$ Department of Medicine, Obafemi Awolowo University Teaching Hospital, Ile-Ife 220282, Nigeria
}

Correspondence should be addressed to Daniel O. Obaseki; danseki@yahoo.com

Received 2 June 2014; Revised 15 September 2014; Accepted 24 September 2014; Published 14 October 2014

Academic Editor: Christian Kähler

Copyright ( 2014 Daniel O. Obaseki et al. This is an open access article distributed under the Creative Commons Attribution License, which permits unrestricted use, distribution, and reproduction in any medium, provided the original work is properly cited.

\begin{abstract}
Introduction. Obstructive sleep apnea (OSA) is a growing public health problem in developing countries. However the burden among commercial drivers is not well described. Methods. The Epworth Sleepiness Scale (ESS) and Berlin questionnaire were administered to interstate commercial road transport drivers to assess the tendency to sleep in daytime and the risk of OSA, respectively. Body mass index (BMI), neck, and waist-hip circumferences were measured. Results. Out of 138 commercial drivers, 124 (90\%) responded and provided complete data. The mean (SD) age, BMI, neck, and waist circumferences were 40.4 (9.3) years, 28.0 (4.6) $\mathrm{kg} / \mathrm{m}^{2}, 40.0(3.0) \mathrm{cm}$, and $92.8(11.1) \mathrm{cm}$, respectively. Twenty-two percent had ESS score above 11 and $36 \%$ of the respondents had a high risk for obstructive sleep apnea. Adjusting for age, BMI, and waist and neck circumferences, the key predictors of road accidents were ESS score above 11 (OR 3.77, 95\% CI 1.18-12.06), self-reported diagnosis of hypertension (OR 4.63, 95\% CI 1.46-14.69), and increasing hip circumference (OR 1.12, 95\% CI 1.01-1.23). Conclusion. Obstructive sleep apnea is common among commercial interstate road drivers in Nigeria and ESS may be a simple tool for assessing accident risk.
\end{abstract}

\section{Introduction}

Obstructive sleep apnea (OSA) is a growing public health challenge [1]. It is characterized by recurring episodes of partial or absolute airway obstruction during sleep resulting in repeated sleep interruptions. When accompanied by daytime somnolence, it is often referred to as obstructive sleep apnea syndrome (OSAS). OSAS is associated with excessive daytime somnolence, cardiovascular morbidity, underperformance in workplace, domestic injuries, and road traffic accidents [2]. There is a large body of evidence that shows that these events may be explained by sleep fragmentation, work patterns, circadian rhythm, and sleep habits like snoring $[3,4]$. About
$15-25 \%$ of the general population in high-income countries is reported to experience excessive daytime sleepiness (EDS) [5] and this may partly be due to obstructive sleep apnea. Though there is a paucity of data on the burden of OSA in many low-income countries, it is generally presumed that OSA is uncommon in these populations. This position has mainly been supported with the argument that the prevalence of obesity is low in low-income economies where low energy diets are staple. However, obesity alone does not explain the variance in the prevalence of OSA across countries. Recent studies in Nigeria have suggested that OSA may be largely underrecognized as high prevalence of snoring and daytime sleepiness has been observed in subsets of the population 
[6-9]. The burden and cost of OSA may be substantial in developing societies especially in costs due to motor crashes and fatalities.

The prevalence of OSA among commercial interstate drivers in Nigeria is unknown. Road accident remains a major cause of death in the country. According to the WHO report on Global Burden of Disease, in 2001 road accident was the tenth leading cause of death in low-income countries [10]. Annually, over 1.2 million lives are lost from road accidents worldwide and $90 \%$ of these deaths occur in low- and middleincome countries [11].

Road traffic accidents are often multifactorial in aetiology; however insights into the possible human and modifiable risk factors may provide useful information for policy makers to reduce the burden of road accidents [12]. We hypothesize that EDS and OSA may be common among Nigerian interstate commercial drivers and may play a contributory role as determinants of road accidents. The present study examined the prevalence of obstructive sleep apnea, excessive daytime sleepiness, and their relationship with self-reported accident history among interstate commercial drivers in Ile-Ife, Nigeria.

\section{Methods}

2.1. Study Location. Ile-Ife is a small university town inhabited by workers of Obafemi Awolowo University and the local dwellers who are mainly farmers and traders. Ile-Ife is widely recognized as the ancestral home of the Yoruba ethnic group in Nigeria. It has a low vehicular traffic and no major industries.

2.2. Study Design. The study was a cross-sectional survey of commercial road transport workers.

2.3. Sample Selection. There is no official database of interstate drivers in Ile-Ife and transport services are loosely organized; most of the local transport service providers have no company labels. We developed a sampling frame through an initial preliminary enumeration of all drivers in the various transport parks. Trained interviewers visited the parks and enumerated all the drivers. Subsequently, the questionnaires were administered to all the drivers who were willing to participate in the survey. Only full time bus and cab drivers operating interstate routes were included and they were interviewed privately.

2.3.1. Berlin Questionnaire. The Berlin questionnaire was administered to all the eligible participants. The Berlin questionnaire is a validated instrument widely used to screen for obstructive sleep apnea syndrome [13]. It includes questions on snoring, witnessed apnea, wake time sleepiness, and selfreported hypertension. It is classified into three categories. Category 1 includes five questions on snoring and witnessed apnea. Category 2 includes three questions on wake time sleepiness and drowsiness behind the steering while Category 3 comprises self-reported diagnosis of high blood pressure and calculated body mass index (BMI). Categories 1 and 2 were considered positive if two or more questions were reported positive at least 3 times/week while Category 3 was positive if the participant has been diagnosed as hypertensive or had BMI greater than $30 \mathrm{~kg} / \mathrm{m}^{2}$. Participants that satisfied the criteria in two or more categories were regarded as having high risk while the others were considered having low risk for obstructive sleep apnea syndrome.

2.3.2. Epworth Sleepiness Scale. Sleepiness was measured using the Epworth Sleepiness Scale (ESS) [14, 15]. The ESS estimates a participant's likelihood to doze off or fall asleep in eight different scenarios associated with daily activities. Each item was measured by a four-point scale and the possible score ranged from zero ( 0$)$ to 24 . A score of more than 11 was used to indicate excessive sleepiness [15].

Snoring was classified as simple for those who snore two times per week or less and habitual for those who snore as loudly as talking and at least three times per week. Nonsnorers were those who answered negative to the question: " $d o$ you snore?" Trained interviewers collected sociodemographic and basic data like age, height, and weight including blood pressure using a portable sphygmomanometer. Neck, waist, and hip circumferences were also measured. The waist circumference was measured at the midway between the iliac crest and the subcostal margin and the hip circumference was measured at the level of maximal circumference around the hip to the nearest centimetre while the participant stood erect with both feet together. The neck circumference was measured at the level of the cricoid cartilage. Information on self-reported accident history was also obtained.

2.4. Data Analysis. The analysis was done using Stata 11.2 (Stata Corp., College Station, TX, USA) [16]. The data were summarized using proportions and frequencies for categorical data but mean and standard deviation for continuous data. The chi-square test was used to test for differences between proportions with and without EDS, OSA, and self-reported motor accident history. To study the influence of several possible explanatory variables on the risk of motor accidents, multiple logistic regression models were developed while adjusting for possible confounders like age, BMI, and neck, waist, and hip circumferences and the results are presented as adjusted odds ratios (OR) with 95\% confidence intervals. A two-sided $P$ value less than 0.05 was considered to indicate statistical significance. Ethical clearance was obtained locally for the survey.

\section{Results}

Of 138 interstate drivers enumerated and requested to participate in this survey, 124 (90\%) consented, completed the questionnaires, and provided anthropometric data. All the drivers were men. Though minimal sociodemographic data could not be obtained from the nonresponders, they did not appear different from the responders in outlook.

Table 1 shows the general characteristics of the participants. The mean (SD) age, weight, and body mass index were 
TABLE 1: General characteristics of the survey respondents $(n=124$, male-100\%)

\begin{tabular}{lcc}
\hline Variable & Mean & SD \\
\hline Age $($ years $)$ & 40.4 & 9.3 \\
Height $(\mathrm{cm})$ & 171.7 & 7.0 \\
Weight $(\mathrm{kg})$ & 82.4 & 12.4 \\
Body mass index $\left(\mathrm{kg} / \mathrm{m}^{2}\right)$ & 28.0 & 4.6 \\
Neck circumference $(\mathrm{cm})$ & 40.0 & 3.0 \\
Waist circumference $(\mathrm{cm})$ & 92.8 & 11.1 \\
Hip circumference $(\mathrm{cm})$ & 101.0 & 11.2 \\
Waist-hip ratio & 0.9 & 0.1 \\
Systolic blood pressure $(\mathrm{mmHg})$ & 132.1 & 17.6 \\
Diastolic blood pressure $(\mathrm{mmHg})$ & 88.4 & 12.4 \\
\hline
\end{tabular}

SD: standard deviation.

40.4 (9.3) years, $82.4 \mathrm{~kg}(12.4)$, and $28 \mathrm{~kg} / \mathrm{m}^{2}$ (4.6), and for neck and waist circumferences the mean (SD) values were $40.0 \mathrm{~cm}(3.0)$ and $92.8 \mathrm{~cm}$ (11.1), respectively. Table 2 shows the distribution of those who responded to the study according to age group. Twenty-two percent of them provided responses suggestive of excessive daytime sleepiness (ESS > 11) while $36 \%$ had a high risk for OSA. Most of those with a high risk of OSA (48\%) were in the 40-49-year age range. Nine percent of the total respondents reported a positive history of witnessed apnea three or more times per week while $29 \%$ had a positive history of road accidents in the past. Fifty-two percent of these road accidents were associated with fatalities (data not shown). Table 3 shows the results of the bivariate analysis of ESS score and OSA risk to potential risk factors and confounders. Those with a high risk for OSA were more likely to have a BMI of $30 \mathrm{~kg} / \mathrm{m}^{2}$ and above and waist circumference above $94 \mathrm{~cm}$ and be hypertensive $(P<0.001)$.

Table 4 shows the relation of self-reported motor vehicle accident to study variables and potential predictors. Respondents with ESS score above 11 (OR: $2.03, P<0.05$ ) and selfreported diagnosis of hypertension (OR: $2.49, P<0.05)$ had significant odds ratio for a self-reported history of vehicle accidents $(P<0.05)$. There was no significant difference in body mass index, waist circumference, age group, or history of witnessed apnea.

Table 5 describes the multivariate logistic regression of self-reported ever history of road accident on potential risk factors and confounders. After adjusting for age and BMI, respondents with an accident history were more likely to have an ESS score above 11 (OR 3.77, 95\% CI 1.18, 12.06) and more likely to be hypertensive (OR 4.63 , 95\% CI 1.46, 14.69). In addition for every $\mathrm{cm}$ increase in hip circumference, the likelihood for an accident increased significantly by $12 \%$ (OR 1.12 , 95\% CI 1.01-1.23), adjusting for waist circumference, age, and BMI.

\section{Discussion}

Our results show that $22 \%$ of interstate commercial drivers experience excessive daytime sleepiness. In addition, 36\% percent of the drivers included in the survey were found to have a high risk of obstructive sleep apnea. ESS score above 11, self-reported diagnosis of hypertension, and increasing hip circumference were independent risk factors for motor accidents history after adjusting for age, self-report of snoring, body mass index, and neck and waist circumferences.

The gold standard for diagnosing obstructive sleep apnea is full polysomnography or at least a respiratory polysomnography with measures of sleep interruptions, oxygen saturation, oronasal flow, or chest movements. However, the Berlin questionnaire is a useful screening tool that has been shown to be highly sensitive, specific, and predictive for respiratory disturbances during sleep [13].

Road traffic accidents are among the leading causes of death worldwide especially in low-income countries [11]. Several factors are involved including poor road infrastructure, inadequate implementation of driving codes, and inattention to potentially correctable human factors $[17,18]$. Among these is obstructive sleep apnea syndrome. We are unaware of any study in Nigeria that has investigated the prevalence and risk of OSA among commercial interstate drivers. Our sample is unlikely to suffer from notable bias in selection as we engaged all willing drivers operating a wide array of interstate routes and distances in Nigeria ranging from 50 to $700 \mathrm{~km}$. In addition, $90 \%$ of those contacted responded and provided complete data.

We found that $22 \%$ of commercial interstate drivers in IleIfe, Nigeria, frequently experience daytime sleepiness while driving, and amongst these $43 \%$ had a high risk for OSA. Prevalence of EDS among Nigerian adults is reported to be under 20\% [7], but higher figures often exist in studies on commercial drivers. It is unclear why there is a difference in prevalence rates of EDS between the general population and commercial drivers. Howard and colleagues reported a similar observation in a survey of a large population of commercial drivers in Australia [3]. They found that $24 \%$ of commercial drivers frequently experience daytime sleepiness against $10.9 \%$ in working adults in the general population. In addition, the degree of sleepiness correlated proportionately to the risk for accidents. It should be noted, however, that $37 \%$ of the drivers in their sample were involved in night shift work. This potentially confounds the report, as sleep deprivation and OSA are independently associated with daytime sleepiness. Though the present survey did not specifically obtain information on sleep quality and duration, night shift driving is not a regular practice in the community where this study took place. It may thus be safe to presume that a substantial proportion of the reports of daytime sleepiness in our respondents are unlikely to be explained by sleep restriction due to night shift work.

We also observed that $36 \%$ of the drivers in our sample had a high risk for OSA. This proportion ranged from $12 \%$ in those aged $20-29$ to $48 \%$ in those aged $40-49$ years. A similar survey in Nigeria which used the Berlin questionnaire in a general population sample of working adults found that $22 \%$ of men were at a high risk for OSA [7]. Some other studies have reported OSA estimates ranging between 25\% and $75 \%$. This wide range may be related to the use of varied methods 
TABLE 2: Distribution of responses by age group of the participants.

\begin{tabular}{|c|c|c|c|c|c|}
\hline Age group (years) & \multicolumn{4}{|c|}{$N(\%)$} & Total \\
\hline \multicolumn{6}{|l|}{ ESS score } \\
\hline ESS > 11 & $5(20)$ & $9(36)$ & $7(28)$ & $4(16)$ & $25(22)$ \\
\hline $\mathrm{ESS} \leq 11$ & $8(9)$ & $29(32)$ & $41(45)$ & $13(14)$ & $91(78)$ \\
\hline \multicolumn{6}{|l|}{ OSA risk } \\
\hline Low risk & $8(11)$ & $26(35)$ & $28(38)$ & $12(16)$ & $74(64)$ \\
\hline High risk & $5(12)$ & $12(28)$ & $20(48)$ & $5(12)$ & $42(36)$ \\
\hline \multicolumn{6}{|l|}{ Snoring } \\
\hline Nonsnorer & $5(9)$ & $20(38)$ & $20(38)$ & $8(15)$ & $53(45)$ \\
\hline Simple snorer & $1(4)$ & $6(24)$ & $14(56)$ & $4(16)$ & $25(22)$ \\
\hline Habitual snorer & $7(18)$ & $12(32)$ & $14(37)$ & $5(13)$ & $38(33)$ \\
\hline \multicolumn{6}{|l|}{ Witnessed apnea } \\
\hline None or 1-2 times/week & $8(8)$ & $34(32)$ & $48(45)$ & $16(15)$ & $106(91)$ \\
\hline 3 times/week or more & $5(50)$ & $4(40)$ & - & $1(10)$ & $10(9)$ \\
\hline \multicolumn{6}{|l|}{ Waist circumference } \\
\hline Below or equal to $94 \mathrm{~cm}$ & $10(16)$ & $23(36)$ & $22(34)$ & $9(14)$ & $64(55)$ \\
\hline Above $94 \mathrm{~cm}$ & $3(6)$ & $15(29)$ & $26(50)$ & $8(15)$ & $52(45)$ \\
\hline \multicolumn{6}{|c|}{ Self-reported motor accident history } \\
\hline Yes & $4(12)$ & $12(36)$ & $11(34)$ & $6(18)$ & $33(29)$ \\
\hline No & $9(11)$ & $24(31)$ & $35(44)$ & $11(14)$ & $79(71)$ \\
\hline
\end{tabular}

OSA: obstructive sleep apnea; ESS: Epworth Sleepiness Scale.

TABLE 3: Bivariate analysis of obstructive sleep apnea and excessive daytime sleepiness.

\begin{tabular}{|c|c|c|c|c|c|c|c|c|c|c|c|}
\hline \multirow{3}{*}{ Variables } & \multirow{3}{*}{ Total respondents } & \multicolumn{5}{|c|}{ Epworth Sleepiness Scale } & \multicolumn{5}{|c|}{ Obstructive sleep apnea } \\
\hline & & \multicolumn{2}{|c|}{ ESS score $>11$} & \multicolumn{2}{|c|}{ ESS score $\leq 11$} & \multirow{2}{*}{$P$ value } & \multicolumn{2}{|c|}{ Low risk } & \multicolumn{2}{|c|}{ High risk } & \multirow{2}{*}{$P$ value } \\
\hline & & $N$ & $\%$ & $N$ & $\%$ & & $N$ & $\%$ & $N$ & $\%$ & \\
\hline \multicolumn{12}{|l|}{ Age group } \\
\hline $20-29$ & 13 & 5 & 38.5 & 8 & 61.5 & \multirow{4}{*}{0.293} & 8 & 61.5 & 5 & 38.5 & \multirow{4}{*}{0.720} \\
\hline $30-39$ & 38 & 9 & 23.7 & 29 & 76.3 & & 26 & 68.4 & 12 & 31.6 & \\
\hline $40-49$ & 48 & 7 & 14.5 & 41 & 85.4 & & 28 & 58.3 & 20 & 41.7 & \\
\hline 50 and above & 17 & 4 & 23.5 & 13 & 76.5 & & 12 & 70.6 & 5 & 29.4 & \\
\hline \multicolumn{12}{|l|}{$\operatorname{BMI}\left(\mathrm{kg} / \mathrm{m}^{2}\right)$} \\
\hline Less than or equal to 24 & 26 & 5 & 19.2 & 21 & 80.8 & \multirow{3}{*}{0.481} & 21 & 80.8 & 5 & 19.2 & \multirow{3}{*}{0.000} \\
\hline $25-29$ & 50 & 9 & 18.0 & 41 & 82.0 & & 45 & 90.0 & 5 & 10.0 & \\
\hline 30 and above & 47 & 13 & 27.7 & 34 & 72.3 & & 15 & 31.9 & 32 & 68.1 & \\
\hline \multicolumn{12}{|l|}{ Waist circumference } \\
\hline Below or equal to $94 \mathrm{~cm}$ & 70 & 15 & 21.4 & 55 & 78.6 & \multirow{2}{*}{0.915} & 56 & 80.0 & 14 & 20.0 & \multirow{2}{*}{0.000} \\
\hline Above $94 \mathrm{~cm}$ & 54 & 12 & 22.2 & 42 & 77.8 & & 26 & 48.2 & 28 & 51.8 & \\
\hline \multicolumn{12}{|l|}{ Waist-hip ratio } \\
\hline Below or equal to 0.95 & 83 & 14 & 16.9 & 69 & 83.1 & \multirow{2}{*}{0.046} & 52 & 62.6 & 31 & 37.4 & \multirow{2}{*}{0.476} \\
\hline Above 0.95 & 36 & 12 & 33.3 & 24 & 66.7 & & 25 & 69.4 & 11 & 30.6 & \\
\hline \multicolumn{12}{|l|}{ Snoring } \\
\hline Nonsnorer & 61 & 8 & 13.1 & 53 & 86.9 & \multirow{3}{*}{0.001} & 58 & 95.1 & 3 & 4.9 & \multirow{3}{*}{0.000} \\
\hline Simple snorer & 25 & 3 & 12.0 & 22 & 88.0 & & 13 & 52.0 & 12 & 48.0 & \\
\hline Habitual snorer & 38 & 16 & 42.1 & 22 & 57.9 & & 11 & 28.9 & 27 & 71.1 & \\
\hline \multicolumn{12}{|l|}{$\begin{array}{l}\text { Self-reported Diagnosis of } \\
\text { hypertension }\end{array}$} \\
\hline Yes & 23 & 9 & 39.1 & 14 & 60.9 & \multirow{2}{*}{0.025} & 5 & 21.7 & 18 & 78.3 & \multirow{2}{*}{0.000} \\
\hline No & 101 & 18 & 17.8 & 83 & 82.2 & & 77 & 76.2 & 24 & 23.8 & \\
\hline \multicolumn{12}{|l|}{ Witnessed apnea } \\
\hline 2 times/week or less & 110 & 22 & 20.0 & 88 & 80.0 & 0.030 & 73 & 66.4 & 37 & 33.6 & 0299 \\
\hline 3 times/week or more & 10 & 5 & 50.0 & 5 & 50.0 & & 5 & 50.0 & 5 & 50.0 & \\
\hline
\end{tabular}

OSA: obstructive sleep apnea and ESS: Epworth Sleepiness Scale. 
TABLE 4: Self-reported motor accident history and potential risk variables.

\begin{tabular}{|c|c|c|c|c|}
\hline \multirow{2}{*}{ Variables } & \multicolumn{4}{|c|}{ Self-reported motor vehicle accident } \\
\hline & $N$ & $\%$ & OR & $P$ value \\
\hline \multicolumn{5}{|l|}{ Age group } \\
\hline $20-29$ & 4 & 30.8 & - & \multirow{4}{*}{0.746} \\
\hline $30-39$ & 12 & 33.3 & 1.08 & \\
\hline $40-49$ & 11 & 23.9 & 0.78 & \\
\hline 50 and above & 6 & 35.3 & 1.15 & \\
\hline \multicolumn{5}{|l|}{ Body mass index $\left(\mathrm{kg} / \mathrm{m}^{2}\right)$} \\
\hline Less than or equal to 24 & 9 & 36.0 & - & \multirow{3}{*}{0.583} \\
\hline $25-29$ & 12 & 24.5 & 0.68 & \\
\hline 30 and above & 13 & 28.9 & 0.80 & \\
\hline \multicolumn{5}{|l|}{ Waist circumference } \\
\hline Below or equal to $94 \mathrm{~cm}$ & 21 & 30.4 & - & \multirow{2}{*}{0.722} \\
\hline Above $94 \mathrm{~cm}$ & 14 & 27.4 & 0.90 & \\
\hline \multicolumn{5}{|l|}{ Waist-hip ratio } \\
\hline Below or equal to 0.95 & 25 & 31.2 & - & \multirow{2}{*}{0.494} \\
\hline Above 0.95 & 9 & 25.0 & 0.80 & \\
\hline \multicolumn{5}{|l|}{ Snoring } \\
\hline Nonsnorer & 16 & 26.7 & - & \multirow{3}{*}{0.725} \\
\hline Simple snorer & 7 & 28.0 & 1.05 & \\
\hline Habitual snorer & 12 & 34.3 & 1.28 & \\
\hline \multicolumn{5}{|l|}{ ESS score } \\
\hline Above 11 & 13 & 48.2 & 2.03 & \multirow{2}{*}{0.014} \\
\hline 11 or below & 22 & 23.7 & - & \\
\hline \multicolumn{5}{|l|}{ Self-reported hypertension } \\
\hline Yes & 13 & 56.5 & 2.49 & \multirow{2}{*}{0.001} \\
\hline No & 22 & 22.7 & - & \\
\hline \multicolumn{5}{|l|}{ Obstructive sleep apnea } \\
\hline Low risk & 21 & 26.2 & - & \multirow{2}{*}{0.320} \\
\hline High risk & 14 & 35.0 & 1.34 & \\
\hline \multicolumn{5}{|l|}{ Witnessed apnea } \\
\hline None or 1-2 times/week & 31 & 29.3 & - & \multirow{2}{*}{0.479} \\
\hline 3 times/week or more & 4 & 40.0 & 1.37 & \\
\hline
\end{tabular}

ESS: Epworth Sleepiness Scale and OR: odds ratio.

and tools in the surveys. Howard et al. reported a prevalence rate of $54 \%$ based on questionnaire sample and $60 \%$ based on polysomnography [3]. Questionnaire estimates of OSA are more likely to be underestimates as screening tools may miss the early stages of sleep disorders. This possibly implies that the prevalence of OSA among road transport drivers in Nigeria may even be higher than presently reported.

The odds ratio of a vehicle crash was threefold higher in those with ESS score greater than 11 and over four times more likely in those who reported previous diagnosis of hypertension after controlling for age, self-report of snoring, body mass index, and neck and waist circumferences.

Our study corroborates several previous reports, which showed that excessive daytime sleepiness constitutes a major risk for various kinds of injuries including domestic, occupational, and motor vehicle accidents $[15,19]$. About $15-25 \%$ of motor vehicle accidents may be attributable to sleep problems [3]. Sleepiness on the wheel is due to several factors including night shifts, obesity, or sleep apnea $[18,19]$. Drivers are generally advised to avoid driving if they feel sleepy; however it remains unclear at what objective levels of sleepiness driving should be prohibited or at what level it should constitute an offence as in alcohol related driving issues.

Interestingly, we observed that respondents with a history of motor vehicle accidents were more likely to have been previously diagnosed hypertensive. Hypertension is known to be prevalent in patients with sleep apnea and sleep disorders have been reported frequently in patients who have essential hypertension [20,21]. This association between sleep and hypertension appears to be independent of age, sex, or obesity. However, from the results of the present study, hypertension also seems to pose an independent risk for motor accidents. This is not well understood as there is sparse information in the literature on this subject. It is worth noting however that unknown and unmeasured variables including comorbidities or apnea-hypopnea index, which is closely correlated with levels of oxygen saturation and wakefulness, may potentially confound this finding. In a meta-analysis of controlled studies of OSA and risk of motor vehicle crashes, Tregear et al. observed that apnea-hypopnea index and oxygen saturation were associated with an increased risk for motor accidents [22].

Obesity is another recognized risk factor for sleep apnea and death in motor vehicle crashes especially among men [23, 24]. Obese drivers tend to have a higher risk for fatal motor crashes [25]. We did not evaluate the effect of OSA on mortality due to motor crashes in the present study and neither did we find any independent link between self-reported vehicle crashes and general obesity (BMI $\geq 30 \mathrm{~kg} / \mathrm{m}^{2}$ ). However, increasing hip circumference was found associated with a positive motor accident history. Our result suggests that regional obesity may be a more important risk factor for motor accidents than general obesity. Further studies are needed to assess the influence of gender and body habitus on the incidence of accidents and the risk of death from accidents.

Our study has some limitations. The sample size is relatively small and few respondents were aged 50 years and above. This may affect the size of the effect reported. Though the direction of the effect is unlikely to change, large studies on the role of EDS and OSA in road accidents in Nigeria are needed. Secondly, we based our report of witnessed apnea on reports by participants' close companions. Polysomnography which is the definitive test for apnea-hypoapnea index was not part of the measurements in the present study, resulting potentially in an underestimate of the prevalence of OSA. Thirdly, our study did not obtain information on use of 
TABLE 5: Logistic regression of self-reported motor vehicle accident history and risk factors.

\begin{tabular}{|c|c|c|c|c|c|c|c|c|c|c|}
\hline & \multicolumn{5}{|c|}{ Unadjusted } & \multicolumn{5}{|c|}{ Adjusted } \\
\hline & OR & SE & \multicolumn{2}{|c|}{$95 \% \mathrm{CI}$} & $P$ value & OR & SE & \multicolumn{2}{|c|}{$95 \% \mathrm{CI}$} & $P$ value \\
\hline \multicolumn{11}{|c|}{ Ever motor accident } \\
\hline Age & 1.01 & 0.02 & 0.97 & 1.05 & 0.72 & 1.01 & 0.03 & 0.94 & 1.08 & 0.84 \\
\hline ESS > 11 (ref.: ESS $\leq 11)$ & 3.00 & 1.37 & 1.23 & 7.32 & 0.02 & 3.77 & 2.24 & 1.18 & 12.06 & 0.03 \\
\hline Snoring & 1.27 & 0.51 & 0.58 & 2.81 & 0.55 & 0.82 & 0.46 & 0.27 & 2.43 & 0.72 \\
\hline Neck circumference $(\mathrm{cm})$ & 0.91 & 0.06 & 0.79 & 1.04 & 0.15 & 0.81 & 0.10 & 0.64 & 1.04 & 0.09 \\
\hline Self-reported hypertension & 4.43 & 2.15 & 1.71 & 11.48 & 0.00 & 4.63 & 2.73 & 1.46 & 14.69 & 0.01 \\
\hline Waist circumference $(\mathrm{cm})$ & 1.00 & 0.02 & 0.97 & 1.04 & 0.85 & 0.93 & 0.05 & 0.84 & 1.03 & 0.18 \\
\hline Hip circumference $(\mathrm{cm})$ & 1.02 & 0.02 & 0.99 & 1.06 & 0.25 & 1.12 & 0.06 & 1.01 & 1.23 & 0.03 \\
\hline BMI $\left(\mathrm{kg} / \mathrm{m}^{2}\right)$ & 1.00 & 0.04 & 0.92 & 1.09 & 0.92 & 0.99 & 0.09 & 0.82 & 1.19 & 0.90 \\
\hline
\end{tabular}

OR: odds ratio, SE: standard error, CI: confidence interval, BMI: body mass index, OSA: obstructive sleep apnea, and ESS: Epworth Sleepiness Scale.

alcohol, sleep duration, road quality, or use of stimulants by drivers. These variables would have helped further in interpreting this result. Lastly, there may also be a survival bias as victims of serious accidents leading to death of the driver may have been inadvertently excluded.

Notwithstanding, this study has some strength. The high response rate achieved through a face-to-face interview is an important strength of this study. In addition, the contribution of sleep disorders to road accidents and loss of lives in highways in developing countries like Nigeria is a poorly understood subject; this study hopes to improve upon and, possibly, stimulate more research. There is clearly a need for more research using standard sleep laboratory facilities or at least overnight oximetry, to quantify the burden of OSA in Nigeria.

Our study highlights the need for policy makers to institute and enforce strict driving principles and regulations for commercial drivers. Though the factors responsible for accidents are multidimensional and multifactorial, daytime sleepiness and obstructive sleep apnea are amenable risk factors that can readily be detected through the use of simple screening tools like the ESS.

In conclusion, our study shows that the prevalence of daytime sleepiness and OSA is substantial among the commercial interstate drivers in Ile-Ife, Nigeria, and ESS score above 11 and regional obesity are independent risk factors for motor accidents.

\section{Disclaimer}

The sponsor of the study had no role in the study design, data collection, data analysis, data interpretation, or writing of the report.

\section{Conflict of Interests}

The authors declare that there is no conflict of interests regarding the publication of this paper.

\section{Authors' Contribution}

Daniel O. Obaseki was involved in the design of the study, collected the data, carried out the statistical analyses, and wrote the first draft of the paper. Josephine E. Obaseki, Ibukun Abidoye, Akinjide Adebisi, and Babatunde Olaiya participated in literature review and collection of data and made major comments on the paper. Gregory E. Erhabor was involved in the design of the concept, provided advice and supervision for the study, revised the initial paper plan, and made major comments on the paper. All authors read and approved the final paper. Daniel O. Obaseki is the guarantor of the paper.

\section{Acknowledgments}

The authors wish to express their gratitude to all the participants who participated in this study. The study was partly supported by the Obafemi Awolowo University Hospital.

\section{References}

[1] T. Young, P. E. Peppard, and D. J. Gottlieb, "Epidemiology of obstructive sleep apnea: a population health perspective," The American Journal of Respiratory and Critical Care Medicine, vol. 165, no. 9, pp. 1217-1239, 2002.

[2] T. Young, E. Shahar, F. J. Nieto et al., "Predictors of sleepdisordered breathing in community-dwelling adults: the Sleep Heart Health Study," Archives of Internal Medicine, vol. 162, no. 8, pp. 893-900, 2002.

[3] M. E. Howard, A. V. Desai, R. R. Grunstein et al., "Sleepiness, sleep-disordered breathing, and accident risk factors in commercial vehicle drivers," The American Journal of Respiratory and Critical Care Medicine, vol. 170, no. 9, pp. 1014-1021, 2004.

[4] S. M. Harding, "Complications and consequences of obstructive sleep apnea," Current Opinion in Pulmonary Medicine, vol. 6, no. 6, pp. 485-489, 2000.

[5] X. Liu, M. Uchiyama, K. Kim et al., "Sleep loss and daytime sleepiness in the general adult population of Japan," Psychiatry Research, vol. 93, no. 1, pp. 1-11, 2000. 
[6] O. O. Adewole, H. Adeyemo, F. Ayeni et al., "Prevalence and correlates of snoring among adults in Nigeria," African Health Sciences, vol. 8, no. 2, pp. 108-113, 2008.

[7] O. O. Adewole, A. Hakeem, A. Fola, E. Anteyi, Z. Ajuwon, and G. Erhabor, "Obstructive sleep apnea among adults in Nigeria," Journal of the National Medical Association, vol. 101, no. 7, pp. 720-725, 2009.

[8] O. A. Sogebi, E. A. Oyewole, and O. O. Olusoga-Peters, "Sleep disordered breathing (SDB) experiences associated with snoring in adult Nigerians," African Health Sciences, vol. 11, no. 3, pp. 309-314, 2011.

[9] O. B. Ozoh, N. U. Okubadejo, M. O. Akanbi, and M. G. Dania, "High-risk of obstructive sleep apnea and excessive daytime sleepiness among commercial intra-city drivers in Lagos metropolis," Nigerian Medical Journal, vol. 54, no. 4, pp. 224229, 2013.

[10] A. D. Lopez, C. D. Mathers, M. Ezzati, D. T. Jamison, and C. J. Murray, "Global and regional burden of disease and risk factors, 2001: systematic analysis of population health data," The Lancet, vol. 367, no. 9524, pp. 1747-1757, 2006.

[11] WHO world report on road traffic injury prevention, 2014, http://whqlibdoc.who.int/publications/2004/9241562609.pdf.

[12] M. F. Mohd Yusoff, M. M. Baki, N. Mohamed et al., "Obstructive sleep apnea among express bus drivers in Malaysia: important indicators for screening," Traffic Injury Prevention, vol. 11, no. 6, pp. 594-599, 2010.

[13] N. C. Netzer, R. A. Stoohs, C. M. Netzer, K. Clark, and K. P. Strohl, "Using the berlin questionnaire to identify patients at risk for the sleep apnea syndrome," Annals of Internal Medicine, vol. 131, no. 7, pp. 485-491, 1999.

[14] M. W. Johns, "A new method for measuring daytime sleepiness: the Epworth sleepiness scale," Sleep, vol. 14, no. 6, pp. 540-545, 1991.

[15] M. W. Johns, "Daytime sleepiness, snoring, and obstructive sleep apnea. The Epworth Sleepiness Scale," Chest, vol. 103, no. 1, pp. 30-36, 1993.

[16] L. StataCorp, Stata Version 11.0, StataCorp LP, College Station, Tex, USA, 2009.

[17] J. M. Lyznicki, T. C. Doege, R. M. Davis, and M. A. Williams, "Sleepiness, driving, and motor vehicle crashes," The Journal of the American Medical Association, vol. 279, no. 23, pp. 1908$1913,1998$.

[18] F. O. Oginni, "Causes of road traffic accidents in developing countries," Traffic Accidents : Causes and Outcomes, vol. 225, 2008.

[19] R. L. B. Ellen, S. C. Marshall, M. Palayew, F. J. Molnar, K. G. Wilson, and M. Man-Son-Hing, "Systematic review of motor vehicle crash risk in persons with sleep apnea," Journal of Clinical Sleep Medicine, vol. 2, no. 2, pp. 193-200, 2006.

[20] K. M. Hla, T. B. Young, T. Bidwell, M. Palta, J. B. Skatrud, and J. Dempsey, "Sleep apnea and hypertension. A population-based study," Annals of Internal Medicine, vol. 120, no. 5, pp. 382-388, 1994.

[21] J. A. Dempsey, "Sleep apnea causes daytime hypertension.," The Journal of clinical investigation, vol. 99, no. 1, pp. 1-2, 1997.

[22] S. Tregear, J. Reston, K. Schoelles, and B. Phillips, "Obstructive sleep apnea and risk of motor vehicle crash: systematic review and meta-analysis," Journal of Clinical Sleep Medicine, vol. 5, no. 6, pp. 573-581, 2009.

[23] S. Zhu, P. M. Layde, C. E. Guse et al., "Obesity and risk for death due to motor vehicle crashes," The American Journal of Public Health, vol. 96, no. 4, pp. 734-739, 2006.
[24] G. Slater, M. F. Pengo, C. Kosky, and J. Steier, "Obesity as an independent predictor of subjective excessive daytime sleepiness," Respiratory Medicine, vol. 107, no. 2, pp. 305-309, 2013.

[25] D. Jehle, S. Gemme, and C. Jehle, "Influence of obesity on mortality of drivers in severe motor vehicle crashes," The American Journal of Emergency Medicine, vol. 30, no. 1, pp. 191-195, 2012. 


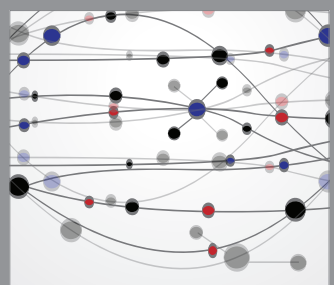

The Scientific World Journal
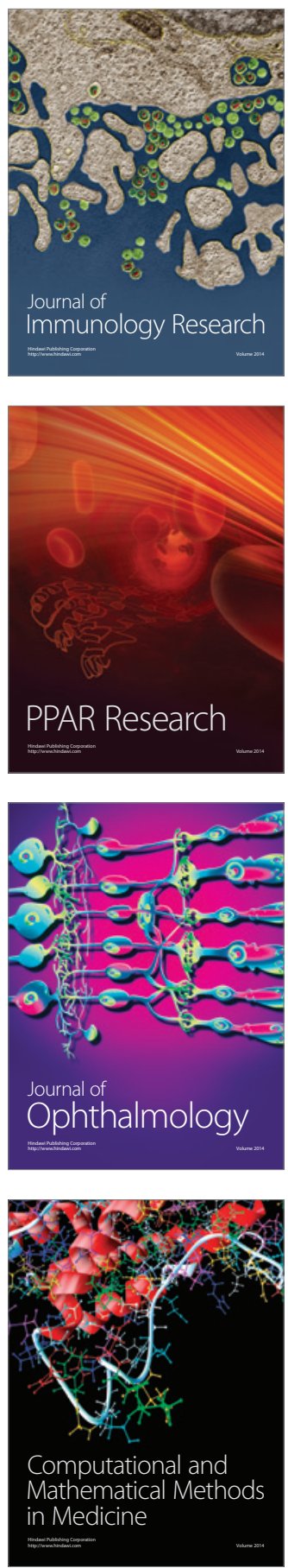

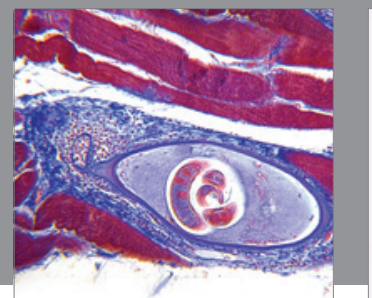

Gastroenterology

Research and Practice
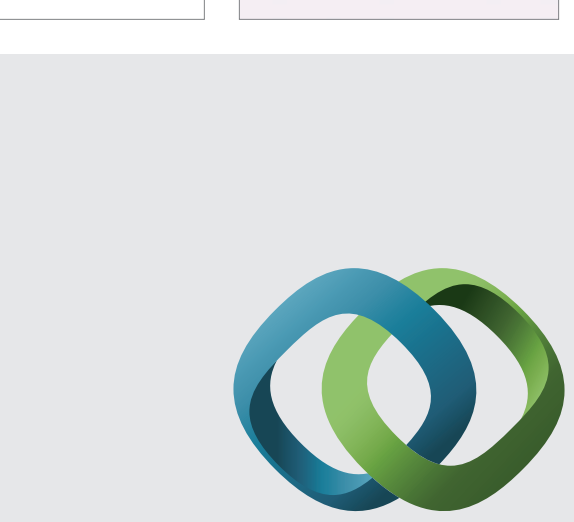

\section{Hindawi}

Submit your manuscripts at

http://www.hindawi.com
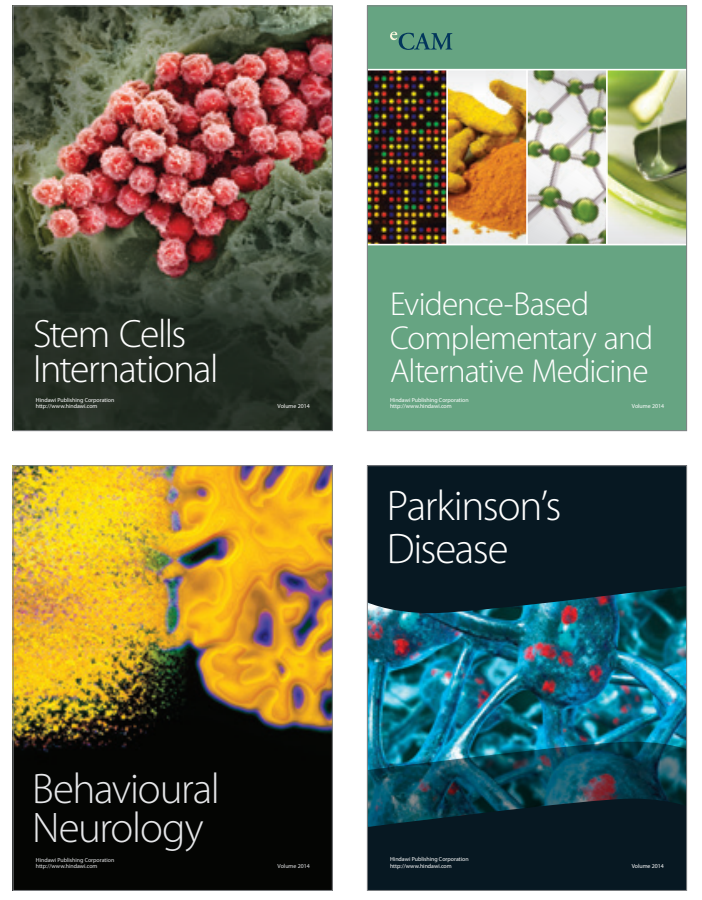
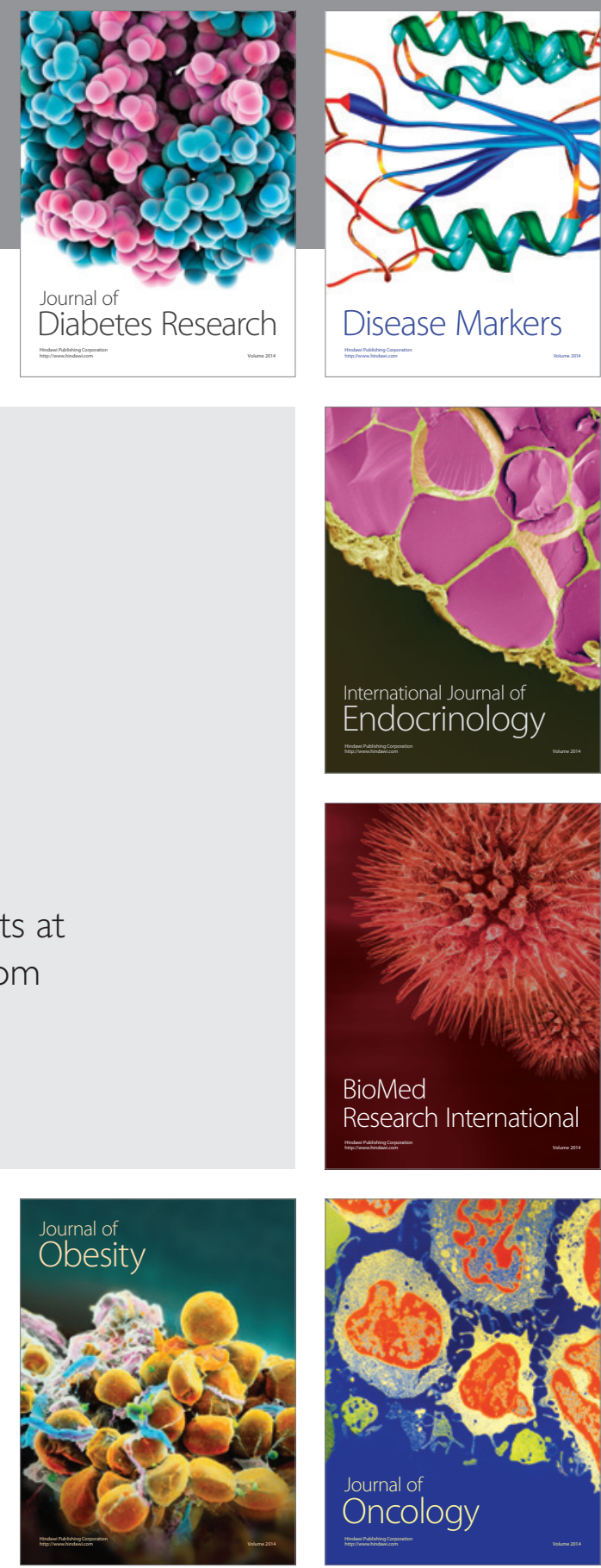

Disease Markers
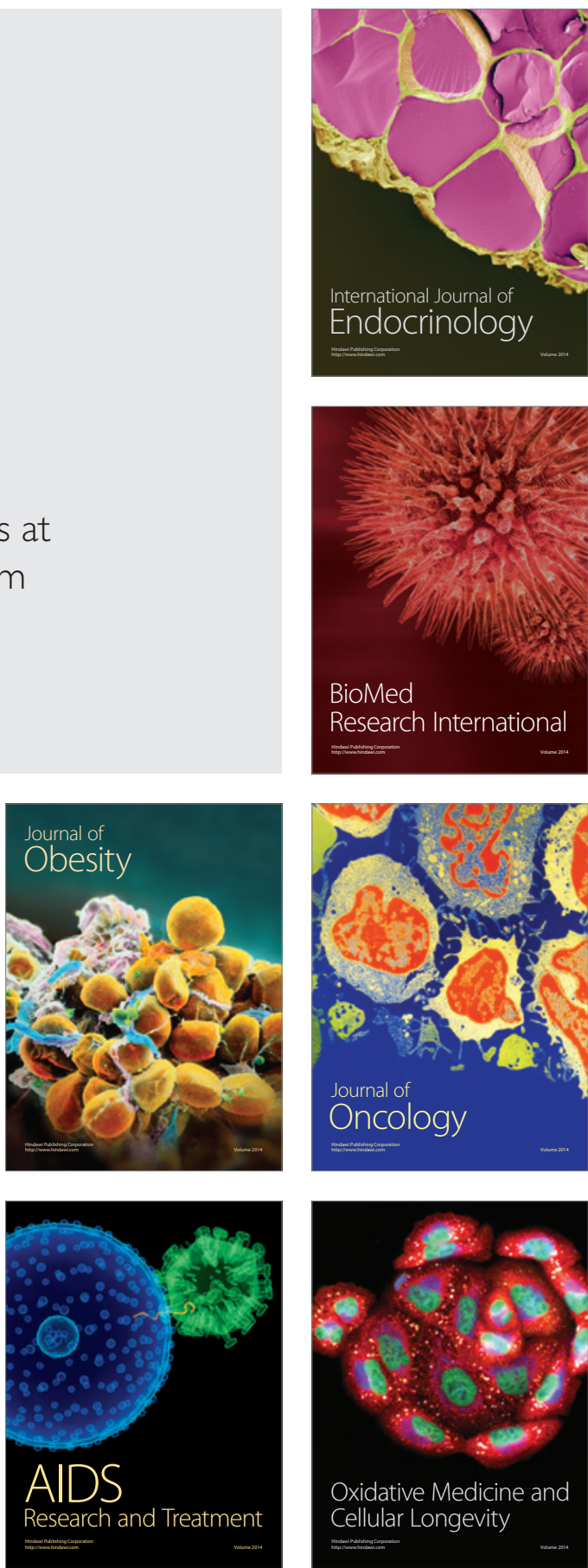